\title{
Measuring the Satisfaction of Participants in Online Learning during the COVID-19 Pandemic: A Large-Scale Analysis
}

\author{
Biao Li', Quanlong Guan'1*, Zhenyu He1, Weiqi Luo ${ }^{1,2}$, Xingyu Zhu ${ }^{3}$ \\ ${ }^{1}$ College of Information Science and Technology, Jinan University, Guangzhou, China \\ ${ }^{2}$ Guangdong Institute of Smart Education, Guangzhou, China \\ ${ }^{3}$ Science and Technology Office, Jinan University, Guangzhou, China \\ Email: biaoli@stu2019.jnu.edu.cn, ^gql@jnu.edu.cn, tzhenyuhe@jnu.edu.cn, luoweiqi@jnu.edu.cn, 16828611@qq.com
}

How to cite this paper: Li, B., Guan, Q. L., He, Z. Y., Luo, W. Q., \& Zhu, X. Y. (2021). Measuring the Satisfaction of Participants in Online Learning during the COVID-19 Pandemic: A Large-Scale Analysis. Open Journal of Social Sciences, 9, 396-424. https://doi.org/10.4236/jss.2021.912027

Received: December 2, 2021

Accepted: December 27, 2021

Published: December 30, 2021

Copyright (c) 2021 by author(s) and Scientific Research Publishing Inc. This work is licensed under the Creative Commons Attribution International License (CC BY 4.0).

http://creativecommons.org/licenses/by/4.0/

\begin{abstract}
With the rapid deterioration and widespread of COVID-19, educational institutions around the world have adopted online teaching instead of traditional classroom teaching for uninterrupted learning. Under the large-scale online teaching activities with COVID-19, participant satisfaction needs to be explored. We collected the data of over five million students and parents, as well as nearly a half million teachers' data. For students and teachers, our results show that regions, grades, urban and rural areas have different impacts on satisfaction. For parents, we adopt machine learning and statistical methods to investigate factors affecting satisfaction. In this research, we found some potential problems of participants groups with different characteristics, including technical support, learning resources, and online interaction. At last, this paper puts forward some suggestions on these finding problems. The government's education institutions can make special policies according to different situations.
\end{abstract}

\section{Keywords}

E-Learning, Participant Satisfaction, Questionnaire, Primary Education, Secondary Education

\section{Introduction}

While COVID-19 is spreading globally, many countries are forced to self-quarantine to slow the spread of the virus. The UN Educational, Scientific and Cultural Organization counts that at least 138 countries have closed schools across the country. The suspension of these schools has vastly affected students' learning, 
and the long-term closure of schools will exacerbate educational inequality (Van Lancker \& Parolin, 2020; McQuaide, 2009). This educational inequality will be reflected in regions and urban and rural areas. Trying to achieve academic judgment is the future development direction of education. (Xie, Naminse, Liu, \& Yi, 2020) believe that the Chinese government should narrow the gap between rural residents' access to the Internet and help communities relieve pressure during the COVID-19 epidemic. As mentioned above, we must make changes from traditional face-to-face teaching to online learning. Due to the spread of COVID-19, the country is obliged to apply online teaching, and online learning has become the mainstream learning form during this period. There is no doubt that this will be an opportunity for the development of online education. We will take this opportunity to explore the current adaptability of K-12 students to online learning, and provide some proposals for online education.

The advantage of online learning education is to expand the benefit of education and increase the possibility of learning opportunities, improving student self-learning ability and skills. However, young learners lack self-regulation, and there will be some sharp problems in the online learning process (Barbour \& Reeves, 2009). Previously, a few countries where K-12 education was dominant, like Canada and the United States, had an online education penetration rate of less than 10\% (Barbour \& LaBonte, 2015). Although China has vigorously promoted online education in the past decade and attempted to adopt online education to enrich teaching resources and enhance public services, students who apply online learning are still rare (Huang, Teo, \& Zhou, 2020). There have been some online learning attempts in some economically developed areas of China, but this large-scale online learning is the first time. Therefore, quantitative analyzing the satisfaction in this large-scale online education can improve the effectiveness of online teaching, thereby making the penetration rate of online education higher. Giving some suggestions for online teaching will help improve the effectiveness of online teaching and increase the penetration rate of online education.

Online education plays an indispensable role in future learning. Yan et al. (Yan, Whitelock-Wainwright, Guan, Wen Gaševićand, \& Chen, 2021) obtained $1,170,769$ student data of this large-scale online education and investigated the learning conditions, benefits, and obstacles and their expectations for online education. Based on the analysis of different grades of $\mathrm{K}-12$, they put forward some suggestions for various situations. In addition to surveying students, we also investigated other participants (teachers and parents), expecting to understand the situation of online education from the satisfaction of multiple roles. This paper explores the factors that affect the survey groups' satisfaction and investigates the actual situation of online learning through three types of role groups. Students, teachers, and parents have four levels of satisfaction. It is beneficial to research the distinction between different satisfaction groups. Each role has special surveys, and the questionnaires contain a wide range of questions. When few factors and data affect satisfaction, we can cross-analyze all factors 
and satisfaction. Since we have obtained more than 11 million massive survey data, how should we analyze the validity and reliability of the massive data, and evaluate the satisfaction? This is the lack of current research. So far there is limited previous research in this area.

In this paper, we believe that factors affecting satisfaction should be selected from a large amount of data, so that satisfaction can be accurately analyzed. The amount of data obtained by scholars in the previous research is so tiny that it is impossible to use statistical and machine learning methods to select satisfaction factors. Kun $\mathrm{Li}$ (Li, 2019) obtained 4000 data. But this research can effectively fill this gap. Baber (Baber, 2020) collected 100 undergraduate students' data from different institutions and courses in both South Korea and India. (Gray \& DiLoreto, 2016) collected including 187 participants' complete survey in the final analyses of the data. This paper abandons the empirical selection feature of measuring satisfaction, and uses lasso and CatBoost (Prokhorenkova, Gusev, Vorobev, Dorogush, \& Gulin, 2017) methods to filter out issues that have a weaker impact on non-scale data satisfaction and uses the structural equation model (SEM) (Li, 2019) to measure the impact of different factors in scale data on satisfaction.

Furthermore, students' satisfaction, in this paper, can be understood within six dimensions, including Lecture webcast (Cobb, 2011), Lecture recording (Clark, Strudler, \& Grove, 2015), Teachers' attitude, Teacher online teaching skills, Online learning resources and Online learning platform (Chen, Peng, Yin, Rong, Yang, \& Cong, 2020). For teachers' group, this paper also divides the overall satisfaction into five parts: Teaching materials, Online interaction, Platform and software, Student engagement, and Contrast classroom teaching. For parents, this study seeks to explore the relationships among Online learning status, Advantages of online education, Disadvantages of online education, Parents' attitudes towards online education, Habits cultivated by online education, and satisfaction. This survey is the first attempt that such large-scale online education data of participating groups have been collected. There are few papers to study parents' views on online education. The virus has forced students to study online at home, so we can explore parents' views. During the COVID-19 pandemic, participants have accumulated online teaching experiences. The findings of this study provide policy recommendations to relevant education regarding the future of online education.

\section{Literature Review}

\subsection{Student Satisfaction}

Online learning methods have some influences on students. Nagy, Judit T and Bernsch (Nagy \& Bernschütz, 2016) show that lecture webcasts can significantly improve semester grades and reduce the dropout rate. The learning method of lecture recording is also widely used. (Leadbeater, Shuttleworth, Couperthwaite, \& Nightingale, 2013) believe that this method can encourage students to learn 
after class. Regardless of the learning method, teachers' good attitude is a key member. (Islahi \& Nasrin, 2019) found that if students want to benefit from online teaching, teachers' attitudes need special attention. On this basis, students also pay more attention to the teaching skills of teachers, which can fully mobilize learning enthusiasm and influence students' views on online teaching. In addition to the above, external conditions such as online teaching platforms also play an essential part for students. Online teaching platforms and abundant teaching materials on the Internet are one of the advantages of online education. (Recker, Giersch, Walker, Halioris, Mao, \& Palmer, 2007) explored how learning resources serves teaching activities. Only rational application of teaching resources can maximize the advantages of online education.

In this survey of student satisfaction, it mainly involves learning methods, teaching attitudes and skills, online education platforms and resources. We propose the following six hypotheses:

H1. Lecture webcast significantly predicts student satisfaction.

H2. Lecture recording significantly predicts student satisfaction.

H3. Teacher's attitude significantly predicts student satisfaction.

H4. Teacher's online teaching skills significantly predict student satisfaction.

H5. Online learning resources significantly predict student satisfaction.

H6. Online learning platform significantly predicts student satisfaction.

\subsection{Teacher Satisfaction}

Online learning has many advantages, but there is no offline classroom convenience in communication, which makes the teaching effect greatly reduced. (Ku, Tseng, \& Akarasriworn, 2013) suggested in online education, in particular, interaction is a critical factor in the perception of learning and teacher satisfaction. Moreover, an important manifestation of student-teacher interaction is student engagement in the classroom. Improving classroom engagement can prevent students from distracting. (Gray \& DiLoreto, 2016) investigated the relationship between student engagement and satisfaction. How to improve classroom participation has also become a valuable factor.

Online learning has requirements for equipment, which may increase our costs, and increase the digital divide between students (Cavanaugh, Barbour, \& Clark, 2009). Learning equipment is essential to both teachers and students. An online teaching platform is vital to performing online teaching. Excellent online teaching platforms and software can promote teacher-student communication. Jin (2012) mainly researched the technology platform, indicating that an effective interactive learning platform can not only achieve high-quality learning for students but also help teachers complete teaching tasks efficiently.

In online teaching, teachers can provide students with various types of materials. Abundant teaching materials can effectively improve the teaching effect of teachers so that teachers can accomplish their teaching goals with less effort. It can be expected that teaching materials prepared by themselves in the online classroom are sufficient, which is conducive to the teaching of knowledge. 
This teacher satisfaction survey mainly involves learning materials, online interaction and teaching platforms. Finally, we also study teacher satisfaction in terms of contrast classroom teaching. Therefore, we propose the following five hypotheses:

H1. Teaching materials significantly predicts teacher satisfaction.

H2. Online interaction significantly predicts teacher satisfaction.

H3. Platform and software significantly predicts teacher satisfaction.

H4. Student engagement significantly predicts teacher satisfaction.

H5. Contrast classroom teaching significantly predicts teacher satisfaction.

\subsection{Parents Satisfaction}

At present, online learning have become an indispensable learning mode in the future, and parents are more concerned about the cultivation of students' online learning ability by this large-scale online learning. Digital data can be continuously stored and updated at any time (Gupta, Eastman, \& Swift, 2005), so cultivating students' digital utilization ability is also parents' expectation. Parents expect their children to plan their study time to complete the task, and therefore self-regulated learning skills are also emphasized in online learning (Broadbent \& Poon, 2015; Wang, Shannon, \& Ross, 2013). Online courses during the COVID-19 pandemic promoted our learning ability in all-round aspects.

Comparing the scale data of students and teachers, parents obtain highdimensional non-scale data. Since parent data has high-dimensional characteristics, we apply feature technology for analysis. In the past, scholars implemented feature selection to improve the satisfaction of online teaching. This study adopted feature selection instead of preparing for chi-square analysis. We apply LASSO and CatBoost feature selection, and then perform chi-square analysis through important variables and satisfaction. Thus, the satisfaction of online education can be analyzed with conciseness and efficiency.

(Baber, 2020) used a structural equation model to measure the effects of online class engagement, online learning, and student perceived learning on online education satisfaction during the COVID-19 pandemic. (Gray \& DiLoreto, 2016) analyze student satisfaction by structural equation model, resulting in increasing retention and improving the quality of online teaching and learning. (Li, 2019) also accepted the structural equation model to examine the connection among MOOC learners' demographics, self-regulated learning (SRL) strategy usage, perceived learning, and satisfaction. The results prove that structural equation model is used to evaluate satisfaction with excellent outcomes. The above research results show that the structural equation model is used to evaluate satisfaction with excellent results.

\section{Methodology}

\subsection{Data Preparation}

Due to the full spread of COVID-19, education authorities have to adopt online 
teaching methods to start teaching activities. Due to the particularity of this survey, the subjects of the survey are determined to be students, teachers, and parents. To better understand the views of online education for the above roles, the education authorities began to distribute questionnaires (see Appendix) in March 2020, and data capture was finished in April 2020. The online survey received a total of more than 12 million valid questionnaires, including 5,791,860 student data, 5,822,768 parent data, and 498,481 teacher data. Dirty data are cleaned by the following methods: 1 ) remove empty and illegal values. 2) remove items with irrational time to fill in the questionnaire. 3) mismatch between the school type and grade of data. For example, the school type is middle school, but students in grades 1 - 6 are selected, and the school type is elementary school, but grades $7-12$ are selected, both of which are illegal data. Data cleaning ensures the authenticity of the data. At the moment, students, teachers, and parents contain 5,176,544, 446,599, and 5,050,397 pieces of data.

\subsection{Data Analysis}

The research collects data through questionnaires. Since there is no authoritative questionnaire available for adoption, education researchers and education practitioners are recruited to design the scale. The draft of the questionnaire was sent to teachers in primary and middle schools, and the questionnaire was improved based on their proposal. Finally, a four-point Likert scale $(1=$ not satisfied, $2=$ average, 3 = satisfied, $4=$ very satisfied) was formed to evaluate students and teachers. Details are available in Appendix. The questions in the questionnaire include Single-response MCQ and Multiple-response MCQ.

\subsubsection{Scale Data}

This research is based on the data type. The data of students and teachers are scale data. To measure the mutual influence of various factors and satisfaction, and fully reflect the factor information and influence, we prefer to adopt the structural equation model to analyze the satisfaction. For scale data, we conduct research separately from urban and rural areas, different regions and grades, and investigate the impact of various factors on satisfaction. Therefore, we designed a scale to answer "How satisfied are you with the following aspects of online learning?". The student scale contains six variables: lecture webcast (LW), lecture recording (LR), teacher attitude (TA), teacher online teaching skills (TOTS), online learning resources (OLR), an online learning platform (OLP).

Teachers and students have individual positions on online education. We have designed a scale for evaluating teacher satisfaction. The five items are applied to measure teacher satisfaction as follows: 1) "How satisfied are you with the online teaching materials that you have compiled and prepared?". 2) "How satisfied are you with the effect of online education interaction?". 3) "How satisfied are you with the effect of teaching platforms and software on online education?". 4) "How satisfied are you with the level of student engagement in online learning?". 5) "Compared with the effect of classroom teaching, how satisfied are you with 
online teaching?". In brief, the teacher scale contains five variables: teaching materials (TM), online interaction (OI), platform and software (PAS), student engagement (SE), and contrast classroom teaching (CCT).

\subsubsection{Non-Scale Data}

Parent data, non-scale data, adopts the LASSO and CatBoost method to select the factors that have a greater impact on satisfaction to perform the chi-square test, and calculate the Cramer's $V$ to evaluate the strength of the association. Questionnaire details are available in Appendix. Ultimately, we use the SHAP method to explain the results of the machine learning method of boost. This approach can not only speed up the selection of satisfaction-related attributes, but also accurately capture the attributes associated to satisfaction.

LASSO: Lasso was first proposed by Robert Tibshirani in 1996 (Tibshirani, 1996), and the author conducted a retrospective study on the method in 2011 (Tibshirani, 2011). The main idea is to construct a first-order penalty function to obtain a refined model and perform feature selection by finally determining the coefficient of some variables as 0 . Because of the high-dimensional data, we adopt LASSO to get valuable information to measure satisfaction. LASSO can effectively reduce the data dimensionality and realize variable selection of high-dimensional data. The mathematical form of LASSO is as follows:

$$
\arg \min \left\{\sum_{i=1}^{n}\left(y_{i}-\beta_{0}-\sum_{j=1}^{p} \beta_{j} x_{i j}\right)^{2}+\lambda \sum_{j=1}^{p}\left|\beta_{j}\right|\right\}
$$

where $n$ means the total sample size is 5,050,397, $p$ indicates the number of features is $46, x_{i j}$ denotes independent variable and represents the questionnaire question and option, $y_{i}$ denotes dependent variable and represents parent satisfaction, $\lambda>0$ means penalty coefficient, controlling the number of selected variables. The value of $\lambda$ obtains the optimal value through the cross-validation method, as shown in Figure 1.

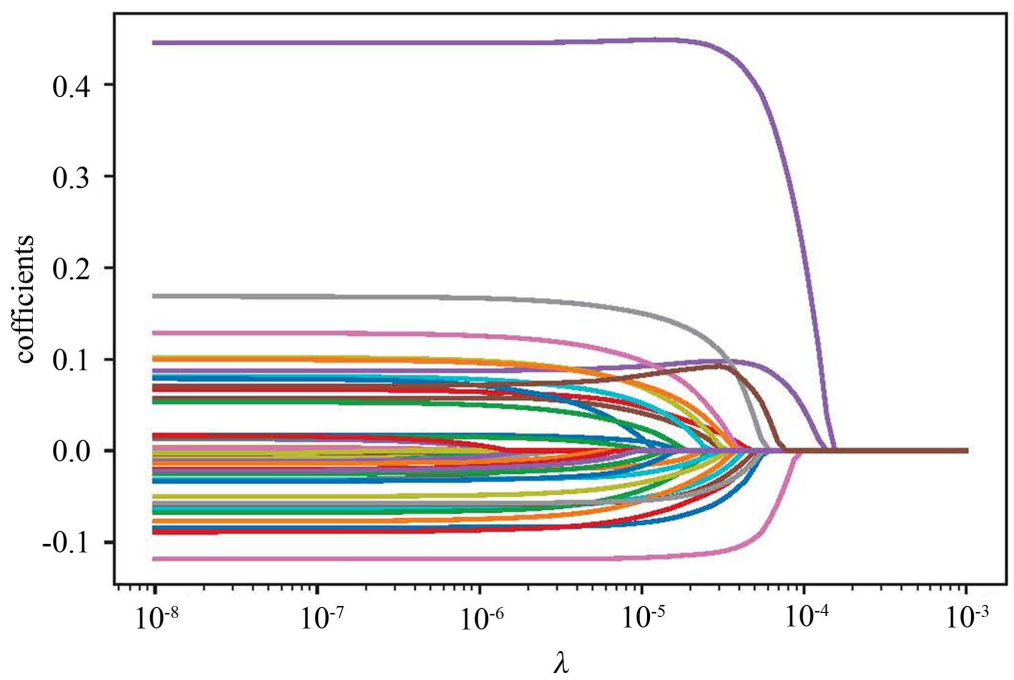

Figure 1. Coefficient path. 
Input the optimal $\lambda=1.26 \times e^{-8}$ into the model, and select the questions that are related to the parents' satisfaction, as shown in Table 1.

CatBoost. All parent questionnaires are categorical data, and the CatBoost algorithm can serve to select features that affect satisfaction. The CatBoost algorithm has three advantages: 1) specially treat category features. 2) Combining category features can optimize the connections between features, which enriches the feature dimension. 3) The base model of CatBoost uses oblivious trees (Prokhorenkova et al., 2017).

Category features. To reduce over-fitting when dealing with parent categorical variables, CatBoost adopts an effective strategy. CatBoost adopts the Greedy Target Statistics method to add prior distribution items, which can decrease the influence of noise and low-frequency categorical data on the data distribution (Diao, Niu, Zang, \& Chen, 2019).

$$
\hat{x}_{k}^{i}=\frac{\sum_{j=1}^{n}\left[x_{j}^{i}=x_{k}^{i}\right] \cdot y_{j}+a P}{\sum_{j=1}^{n}\left[x_{j}^{i}=x_{k}^{i}\right]+a}
$$

Assume that the parent dataset of examples $D=\left\{\left(x_{k}, y_{k}\right)\right\}_{k=1, \cdots, n}$, where $x^{k}=\left(x_{k}^{1}, \cdots, x_{k}^{m}\right)$ is a random vector of $m$ features and $y_{k} \in \mathbb{R}$ is a target (parent satisfaction). Among them, $m$ and $n$ represent 46 and 5,050,397. A priori value $P$ and parameter $a>0$, namely the priori weight are added, which contributes to reducing the noise obtained from the low frequency category.

Feature combinations. Another important detail of CatBoost is using combinations of categorical features as additional categorical features which captures high-order dependencies. We arbitrarily combine all the category attributes of the parent data into a new feature, which can solve the problem of information loss by Equation (2). However, as the dimension of data features increases, the combination of features will increase exponentially. Therefore, CatBoost greedily boost constructs combinations. Namely, for each split of a tree, the average value

Table 1. Questions selected by LASSO from the parent questionnaire.

\begin{tabular}{lc}
\hline \multicolumn{1}{c}{ Question Text } & \multicolumn{1}{c}{ Question Types } \\
\hline $\begin{array}{l}\text { Q10. What is your child's learning status when } \\
\text { learning online? }\end{array}$ & Yes/No Questions \\
Q12. What do you think are the benefits of online & Multiple-response MCQ \\
education? & \\
$\begin{array}{l}\text { Q13. What do you think are the deficiencies } \\
\text { of online learning? }\end{array}$ & Multiple-response MCQ \\
Q15. What is your attitude towards the & Yes/No Questions \\
implementation of online teaching & \\
during the epidemic? & \\
Q16. Which of the following learning habits \\
do you think your children have developed \\
through online education during the epidemic?
\end{tabular}


of the replaced category labels is used as the criterion for node splitting. CatBoost connects all the combinations and categorical features of the current tree with all the categorical features in the dataset, and dynamically converts the new categorical combination features into numerical features.

SHAP. Shapley Additive exPlanation (SHAP) is a unified approach to interpreting the output of any Machine Learning model. SHAP relates game theory to local interpretation and represents the only possible consistent and locally accurate additive feature attribution method according to expectation. SHAP interprets Shapley values (Shapley, 1953) as Additive feature attribution methods. SHAP interprets the predicted value of parent satisfaction in the CatBoost model as the sum of the attribution values of each input feature. The following is the definition of the additive feature attribution method:

$$
g\left(z^{\prime}\right)=\phi_{0}+\sum_{i=1}^{M} \phi z_{i}^{\prime}
$$

$g$ is an explanation model, where $z^{\prime} \in\{0,1\}^{M}$ indicates whether the corresponding feature can be observed or not ( 1 or 0$)$. Because the parent data is structured, the characteristics of each instance can be observed. $M$ is the number of CatBoost model features, and $\phi_{i} \in \mathbb{R}$. The $z_{i}^{\prime}$ variables typically represent $i$ feature being observed $\left(z_{i}^{\prime}=1\right)$ or unknown $\left(z_{i}^{\prime}=0\right)$. The $\phi_{i}$ are sharply value.

The output of the Catboost model predicted sample can carve up into the sum of the features SHAP values, and this method serves to explain the CatBoost model.

SHAP Summary Plots. Features with vast Shapley absolute value are major. SHAP summary plots leverage individualized feature attributions to convey all these aspects of a feature's importance while remaining visually concise. Features are first sorted by sum of SHAP values, then dots representing the SHAP values $\phi_{i}^{(j)}$ are plotted horizontally, stacking vertically when they run out of space (Lundberg, Erion, \& Lee, 2018).

To discover the major factors influencing satisfaction, CatBoost selects the feature that considerably affects satisfaction. At the same time, to visualize the performance data, SHAP serves to interpret the model training results. This paper employs CatBoost trained with parent data, and then it is represented by SHAP Summary Plots as shown in Figure 2. To get an overview of which features in the model are the most important, we can plot the SHAP value of each feature for each sample. Figure 2 is based on the sum of SHAP values on all samples, and applies SHAP values to showing the distribution of the impacts respectively feature has on the model output. Red means that the feature value is higher than the predicted value of the CatBoost model, and blue is the opposite.

Considering the factors affecting satisfaction selected by CatBoost (see Figure 2) and the questions selected by LASSO (see Table 2), we finally pick out Q10, Q12, Q13, Q15, Q16 and satisfaction for the chi-square test. The results are shown in Section 4. 
Q10.What is your child's online learning status? Q13.Poor online platform experience

Q13.Poor teacher-student interaction

Q12.Cultivate self-learning ability

Q15.What is your attitude toward online teaching?

Q16.Dedicated course

Q13.More cooperation requirements for parents

Q12.Easy to review

Q13.Children addicted to the Internet

Q12.Learn anytime, anywhere

Q16.Complete homework in time

Q9.Can your child independently use the online learning device?

q12.Diverse learning resources

Q13.Insufficient curriculum resources

Q6.Do you accompany your children in online learning?

Q16.Review

Q13.Lack of group activities, affecting mental

Q12.Access to courses delivered by famous teachers

Q16.Preview

Q16.Take notes skillfully

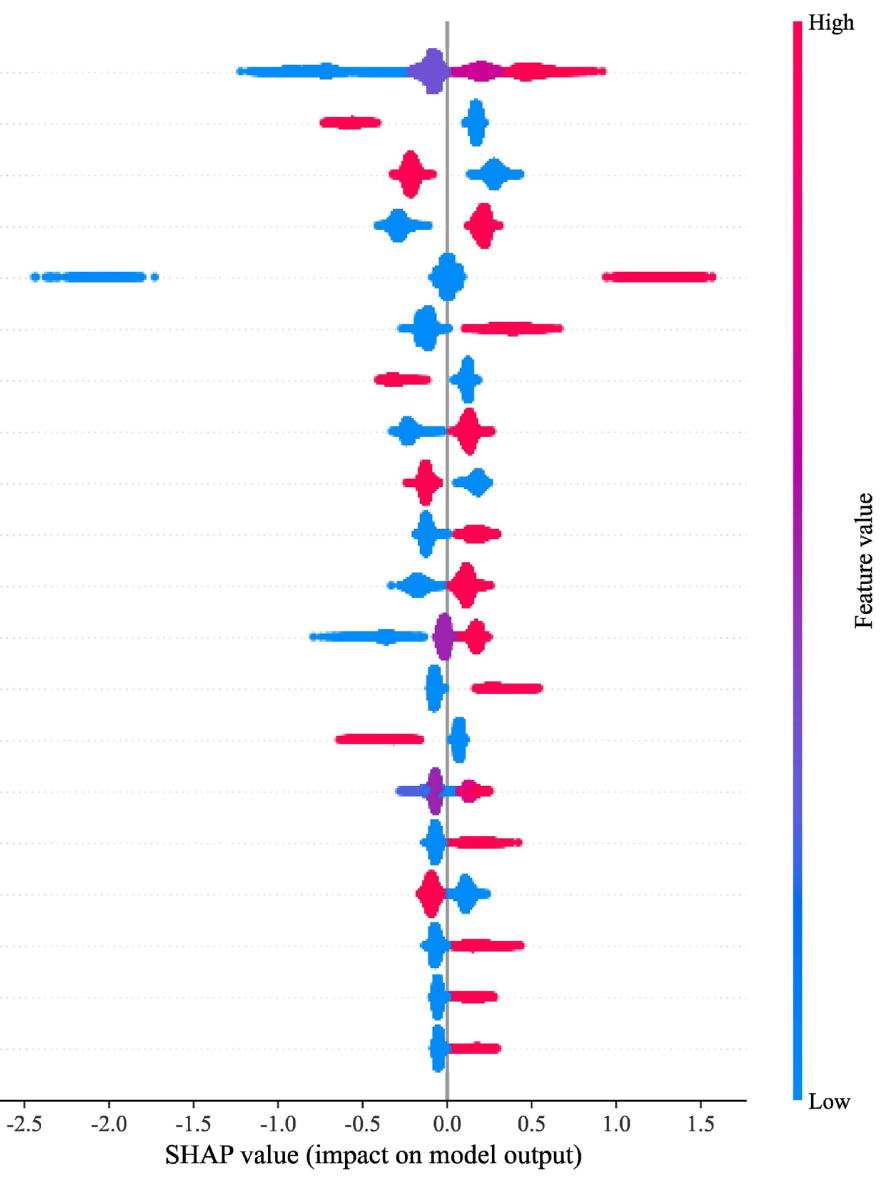

Figure 2. SHAP summary plot of CatBoost model.

Table 2. Results for the overall measurement model.

\begin{tabular}{ccccc}
\hline Construct and item & $\begin{array}{c}\text { Standardized } \\
\text { factor loading }\end{array}$ & $\begin{array}{c}\text { Cronbach's } \\
\text { alpha }\end{array}$ & CR & AVE \\
\hline Lecture webcast & 0.82 & & & \\
Lecture recording & 0.82 & & 0.93 & 0.70 \\
Teacher attitude & 0.74 & 0.94 & & \\
Teacher online teaching skills & 0.77 & & & \\
Online learning resources & 0.89 & & \\
Online learning platform & 0.88 & & \\
\hline
\end{tabular}

\section{Result}

\subsection{Student}

\subsubsection{Measurement Model}

(Kline, 2015) recommends reporting some parameters in the SEM model, including CFI, TLI, RMSEA, SRMR, Chi-square, because the sample size of this study is particularly large $(n=5,791,860)$, Chi-square is inevitably much larger than the general parameters. Based on this particularity, Chi-square is not re- 
ported in this paper. (Hu \& Bentler 1999) provided recommended thresholds for evaluation parameters. The above parameters are shown in Table 2. The SEM indicators in urban and rural areas and different regions can satisfy the recommended threshold, demonstrating the model fits well. Furthermore, high school students slightly surpass the recommended threshold in the RMSEA. But we can consider it close to the standard.

All Student. The CFA results are shown in Table 2. All standardized factor loadings were higher than 0.5 , between 0.74 and 0.89 . Cronbach's alphas were higher than 0.70 (de Barba, Kennedy, \& Ainley, 2016), Composite reliability (CR) was higher than 0.70 (Hair, 2009), and Average variance extracted (AVE) was higher than 0.50 (Fornell \& Larcker, 1981) points out the reliability of items is acceptable.

Students from different regions. In Table 3, in terms of the "lecture webcast", "lecture recording", "teacher attitude", "teacher online teaching skills", "online learning resources", and "online learning platform", students in the South have the highest satisfaction weights in all ways. However, regional differences are not obvious in online education.

Students from urban and rural. As shown in Table 3, in urban and rural areas, the difference between "teacher attitudes" and "teachers online teaching skills" on satisfaction factors reached $4 \%$, which means that "rural" students pay more attention to teacher attitudes and teacher online teaching skills than "urban" students. In other respects, there is no distinction between urban and rural students.

Students from different grades. In Table 3, primary school students' satisfaction factor loading is about $4 \%$ lower than middle schools (junior and high

Table 3. Results for student measurement model.

\begin{tabular}{ccccccc}
\hline & \multicolumn{6}{c}{ Standardized factor loading $(>0.50)$} \\
\cline { 2 - 6 } & LW & LR & TA & TOTS & OLR & OLP \\
\hline South & 0.83 & 0.82 & 0.76 & 0.80 & 0.90 & 0.89 \\
West & 0.81 & 0.81 & 0.76 & 0.78 & 0.89 & 0.88 \\
North & 0.82 & 0.82 & 0.75 & 0.78 & 0.90 & 0.89 \\
Urban & 0.83 & 0.82 & 0.76 & 0.79 & 0.90 & 0.89 \\
Rural & 0.82 & 0.82 & 0.74 & 0.77 & 0.89 & 0.88 \\
Primary & 0.82 & 0.82 & 0.74 & 0.77 & 0.89 & 0.88 \\
Junior & 0.83 & 0.82 & 0.78 & 0.81 & 0.91 & 0.89 \\
High & 0.82 & 0.81 & 0.77 & 0.81 & 0.91 & 0.88 \\
\hline
\end{tabular}

Notes: LW (lecture webcast); LR: (lecture recording); TA (teacher attitude); TOTS (teacher online teaching skills), OLR (online learning resources); OLP (online learning platform). 
school) in "teacher' attitudes" and "teacher online teaching skills", and 2\% lower in "online learning resources" than middle schools. Comparing with middle school students, primary school students are not so sensitive to the above three factors. Primary school students are emotionally immature and have relatively careless attitudes towards teachers teaching, so the influence of teacher attitudes on them is weaker than that of junior and high schools. The knowledge system in primary schools is relatively simple, mainly related to teachers' vivid narration, and the required teaching skills are slightly lower than those in middle schools.

\subsubsection{Structural Model}

The result of the structural equation model shows that the model fits well (CFI = $0.995, \mathrm{TLI}=0.989, \mathrm{RMSEA}=0.057, \mathrm{SRMR}=0.0126$ ), and all of the models reach the robust indicators. Figure 3 shows the graphical results of the path coefficient. In the path figure, the one-way arrow and the two-way arrow respectively play the causal and correlation relationship. Maximum likelihood estimation serves to examine the hypothesized model. The results (see Table 4) support the hypothesized model proposed in Section 3. The results show that all of the hypotheses are significant.

In Figure 3, it can be seen that "online learning resources" and "online learning platform" have the largest weights on student satisfaction in online learning, respectively 0.91 and 0.89 , while online "teacher attitude" has the least impact on student satisfaction, which is 0.76 .

Table 4. Fit indices for the measurement model.

\begin{tabular}{ccccc}
\hline & $\begin{array}{c}\text { Comparative Fit } \\
\text { Index (CFI) }\end{array}$ & $\begin{array}{c}\text { Tucker-Lewis } \\
\text { Index (TLI) }\end{array}$ & RMSEA $^{\mathrm{a}}$ & SRMR $^{\mathrm{b}}$ \\
All & 0.995 & 0.989 & 0.061 & 0.0125 \\
South & 0.995 & 0.989 & 0.062 & 0.0124 \\
East & 0.995 & 0.989 & 0.060 & 0.0126 \\
Western & 0.995 & 0.988 & 0.063 & 0.0132 \\
North & 0.995 & 0.990 & 0.059 & 0.0116 \\
Urban & 0.995 & 0.990 & 0.057 & 0.0126 \\
Rural & 0.993 & 0.985 & 0.072 & 0.0133 \\
Primary & 0.995 & 0.990 & 0.057 & 0.0126 \\
Junior & 0.994 & 0.987 & 0.068 & 0.0125 \\
High & 0.991 & 0.981 & 0.081 & 0.0152 \\
Recommended threshold & $\geq 0.90$ & $\geq 0.90$ & $\leq 0.08$ & $\leq 0.08$ \\
\hline
\end{tabular}

a. Significant Root Mean Square Error of Approximation. b. Significant Standardized Root Mean Square Residual. 


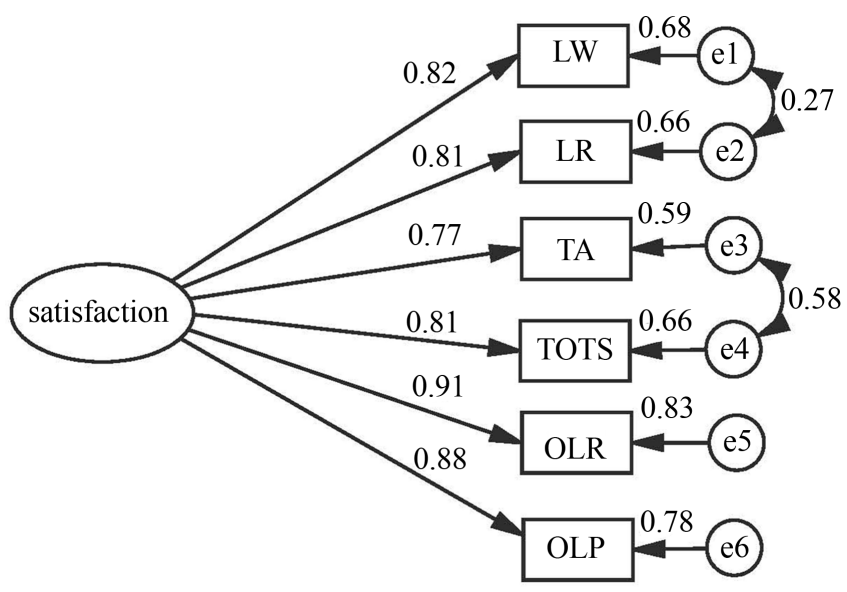

Figure 3. Overall student structural equation model.

Hypothesis 1 indicates lecture webcast (LW) has a significant impact on student satisfaction.

Hypothesis 2 indicates lecture recorded (LR) has a significant impact on student satisfaction.

Hypothesis 3 indicates that teacher attitude (TA) has a significant impact on student satisfaction.

Hypothesis 4 indicates that teacher online teaching skills (TOTS) have a significant impact on student satisfaction.

Hypothesis 5 indicates that online learning resources (OLR) have a significant impact on student satisfaction.

Hypothesis 6 indicates that online learning platform (OLP) has a significant impact on student satisfaction.

\subsection{Student}

\subsubsection{Measurement Model}

As shown in Table 5, all indicators of teachers' overall measurement model can meet the recommendation threshold. Moreover, the SEM indicators in each region, including urban and rural areas, and grades can satisfy the recommendation threshold, demonstrating the model fits well.

All Teachers. The CFA results are shown in Table 6. All standardized factor loadings were higher than 0.5 , between 0.52 and 0.90 . Cronbach's alphas were higher than 0.70 (de Barba, Kennedy, \& Ainley, 2016), Composite reliability (CR) was higher than 0.70 (Hair, 2009), and Average variance extracted (AVE) was higher than 0.50 (Fornell \& Larcker, 1981) pointing out the reliability of items is acceptable.

Teacher from different regions. As shown in Table 7, in "teaching materials", "western" has a larger factor load than the other three regions, $6 \%$ higher than "south" and "north", and $4 \%$ higher than "east". The proportions of "online interaction", "platform and software", "student engagement" and "contrast classroom teaching" in "western" are also higher than those of the other three regions, but the distinction is slight. 
Table 5. Fit indices for the measurement model.

\begin{tabular}{ccccc}
\hline & $\begin{array}{c}\text { Comparative Fit } \\
\text { Index (CFI) }\end{array}$ & $\begin{array}{c}\text { Tucker-Lewis } \\
\text { Index (TLI) }\end{array}$ & RMSEA $^{\text {a }}$ & $S_{R M R^{\mathrm{b}}}$ \\
\hline All & 0.999 & 0.999 & 0.020 & 0.0023 \\
South & 0.999 & 0.998 & 0.019 & 0.0023 \\
East & 0.999 & 0.998 & 0.021 & 0.0025 \\
Western & 0.999 & 0.999 & 0.020 & 0.0021 \\
North & 0.999 & 0.999 & 0.019 & 0.0021 \\
Urban & 0.999 & 0.998 & 0.021 & 0.0025 \\
Rural & 0.999 & 0.999 & 0.019 & 0.0020 \\
Primary & 0.999 & 0.999 & 0.018 & 0.0022 \\
Junior & 0.999 & 0.998 & 0.022 & 0.0029 \\
High & 0.999 & 0.998 & 0.022 & 0.0027 \\
Recommended threshold & $\geq 0.90$ & $\geq 0.90$ & $\leq 0.08$ & $\leq 0.08$ \\
\hline
\end{tabular}

a. Significant Root Mean Square Error of Approximation. b. Significant Standardized Root Mean Square Residual.

Table 6. Results for the overall measurement model.

\begin{tabular}{ccccc}
\hline Construct and item & $\begin{array}{c}\text { Standardized } \\
\text { factor loading }\end{array}$ & $\begin{array}{c}\text { Cronbach's } \\
\text { alpha }\end{array}$ & CR & AVE \\
\hline Teaching materials & 0.52 & & & \\
Online interaction & 0.78 & & 0.87 & 0.58 \\
Platform and software & 0.67 & & & \\
Student engagement & 0.90 & & & \\
Contrast classroom teaching & 0.88 & & & \\
\hline
\end{tabular}

Table 7. Results for teacher measurement model.

\begin{tabular}{cccccc}
\hline & \multicolumn{5}{c}{ Standardized factor loading $(>0.50)$} \\
\cline { 2 - 5 } & TM & OI & PAS & SE & CCT \\
\hline South & 0.50 & 0.77 & 0.67 & 0.90 & 0.88 \\
East & 0.52 & 0.78 & 0.65 & 0.89 & 0.87 \\
Western & 0.56 & 0.80 & 0.68 & 0.90 & 0.89 \\
North & 0.50 & 0.77 & 0.66 & 0.89 & 0.88 \\
Urban & 0.52 & 0.78 & 0.68 & 0.90 & 0.88 \\
Rural & 0.52 & 0.78 & 0.65 & 0.90 & 0.88 \\
Primary & 0.55 & 0.78 & 0.66 & 0.90 & 0.87 \\
Junior & 0.48 & 0.77 & 0.65 & 0.89 & 0.88 \\
High & 0.51 & 0.79 & 0.70 & 0.89 & 0.89 \\
\hline
\end{tabular}

Notes: TM (teaching materials); OI: (online interaction); PS (platform and software); LE (learning engagement), CCT (contrast classroom teaching). 
Teacher from urban and rural. As shown in Table 7, in urban and rural areas, "urban" teachers are in "platform and software" than "ruraP" teachers, and the factor load is $3 \%$ higher. "urban" teacher is more satisfied with online teaching than "rural" teachers. In other respects, there is no distinction between urban and rural teachers.

Teacher from different grades. The standard factor loading of the "Junior" on "Teaching materials" is slightly lower than the 0.5 , but it has little effect. In Table 7, the satisfaction factor of junior school teachers is $7 \%$ and $3 \%$ lower than those of primary school teachers and high school teachers in the "teaching materials", which demonstrates that primary school teachers pay more attention to online teaching materials, followed by high school teachers and junior school teachers. "platform and software" is $5 \%$ lower than high school teachers in junior high school teachers, indicating that for high school teachers, teaching platforms and software can affect their satisfaction even more.

\subsubsection{Structural Model}

The result of the structural equation model shows that the model fits well (CFI = $0.999, \mathrm{TLI}=0.999, \mathrm{RMSEA}=0.020, \mathrm{SRMR}=0.0023)$, and all of the models reach the robust indicators. Figure 4 shows the graphical description of the results of path coefficients. The results show that all the hypotheses rely on the data and significant.

In Figure 4, "student engagement" and "contrast classrooms teaching" have the largest weights in student satisfaction with online courses, respectively 0.90 and 0.88 . On the contrary, "teaching materials" have an influence of 0.52 on teacher satisfaction, which is much smaller than the influence of other factors on teacher satisfaction.

Hypothesis 1 indicates that teaching materials (TM) has a significant impact on student satisfaction.

Hypothesis 2 indicates that online interaction (OI) has a significant impact on student satisfaction.

Hypothesis 3 indicates that platform and software (PAS) has a significant impact on student satisfaction.

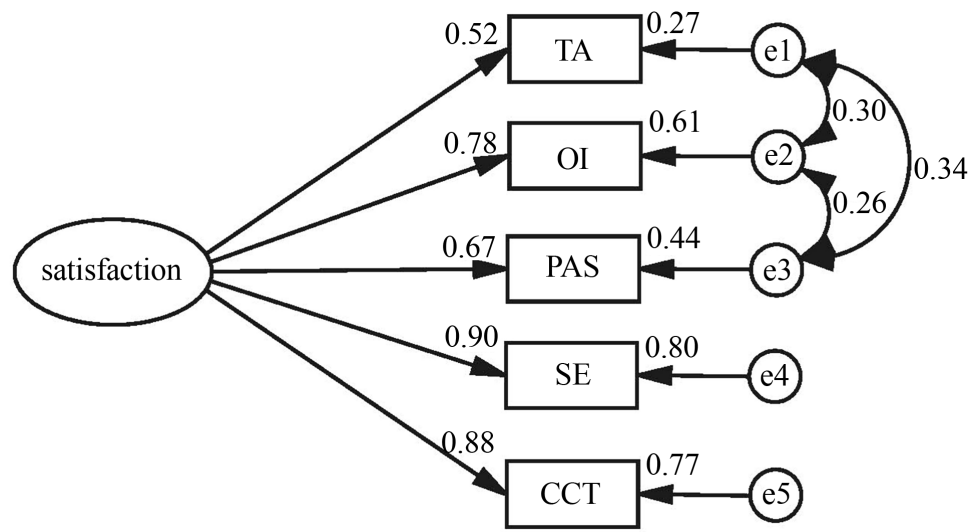

Figure 4. Overall teacher structural equation model. 
Hypothesis 4 indicates that student engagement (SE) has a significant impact on student satisfaction.

Hypothesis 5 indicates that contrast classrooms teaching (CCT) has a significant impact on student satisfaction.

\subsection{Parents}

In this section, parents with different satisfaction levels (very satisfied, satisfied, average, not satisfied) and Q10, Q12, Q13, Q15, Q16 are analyzed based on the cross-tab method. In order to verify whether the differences shown by parents of various satisfaction levels are statistically significant, we performed a chi-square test and calculated Cramer's $V$ to evaluate the strength of the association.

\subsubsection{Online Learning Status}

In Table 8, the learning status and satisfaction have a strong effect size (Cramer's $V=0.442) .42 \%$ of parents were "sometimes attentive, sometimes not attentive", which is the highest proportion in the learning state. Compared with physical classrooms, electronic devices used in online learning can cause most students to be distracted. Only $24 \%$ of the parents chose "able to concentrate on learning", but the percentage of parents with a satisfaction rating of "very satisfied" reached 56\%, which implies that parents' satisfaction with online teaching has a great bond with their children's attention.

\subsubsection{Advantages of Online Education}

The chi-square test shows that all $p<0.001$ in Table 9, indicating that the relationship between parent satisfaction and the advantage of online education is significant. As shown in Table 9, the percentages of parents who regard "easy to review" and "cultivate self-learning ability" are as high as $64.72 \%$ and $57.01 \%$, respectively. Parents are more concerned about course review and children's

Table 8. The results on Q10 surveyed parents' perceptions of their children's online learning status, and the results were presented as percentages. All results are calculated by considering parents with different satisfaction levels. The scores in the same row that are lower than the corresponding All value are marked in bold.

\begin{tabular}{|c|c|c|c|c|c|c|c|c|}
\hline satisfaction & $\begin{array}{c}\text { Very } \\
\text { satisfied }\end{array}$ & Satisfied & Average & $\begin{array}{c}\text { Not } \\
\text { Satisfied }\end{array}$ & All & $\chi^{2}$ & $p$ & $\begin{array}{c}\text { Cramer's } \\
V\end{array}$ \\
\hline Able to concentrate on learning & 56.93 & 35.00 & 14.90 & 5.10 & 24.14 & & & \\
\hline $\begin{array}{l}\text { Be able to concentrate on learning } \\
\text { with supervision }\end{array}$ & 18.22 & 22.74 & 18.15 & 10.01 & 19.24 & & & \\
\hline Sometimes attentive, sometimes not attentive & 20.95 & 37.12 & 49.61 & 33.80 & 42.14 & $988,306.40$ & 0.000 & 0.442 \\
\hline Generally cannot concentrate on studying & 2.13 & 3.16 & 10.96 & 30.65 & 8.98 & & & \\
\hline Not adapted to online learning & 0.97 & 1.30 & 4.95 & 17.71 & 4.29 & & & \\
\hline Don't understand & 0.80 & 0.68 & 1.43 & 2.74 & 2.74 & & & \\
\hline
\end{tabular}

$p<0.001$ : Indicates a significant difference between various satisfaction levels. Cramer's V $=0.1$ has a small effect size, Cramer's $\mathrm{V}$ $=0.3$ has a medium effect size, Cramer's $\mathrm{V}=0.5$ has a strong effect. 
Table 9. The results on Q12 surveyed parents' perceptions of the advantages of online education, and the results are presented as percentages. All results are calculated by considering parents with varying degrees of satisfaction. The scores in the same row that are lower than the corresponding All value are marked in bold.

\begin{tabular}{cccccccccccc}
\hline satisfaction & $\begin{array}{c}\text { Very } \\
\text { satisfied }\end{array}$ & Satisfied & Average $\begin{array}{c}\text { Not } \\
\text { Satisfied }\end{array}$ & All & $\chi^{2}$ & $\begin{array}{c}\text { Cramer's } \\
V\end{array}$ \\
\hline Diverse learning resources & 52.81 & 41.53 & $\mathbf{2 6 . 0 0}$ & $\mathbf{1 2 . 5 6}$ & 32.36 & $242,589.72$ & 0.000 & 0.219 \\
Access to courses delivered & 47.83 & 31.41 & $\mathbf{1 6 . 3 5}$ & $\mathbf{7 . 4 7 3}$ & 23.16 & $294,754.72$ & 0.000 & 0.242 \\
Easy to review & 75.00 & 74.20 & $\mathbf{6 0 . 7 0}$ & $\mathbf{3 5 . 7 9}$ & 64.72 & $237,348.27$ & 0.000 & 0.217 \\
Learn anytime, anywhere & 57.49 & 53.13 & $\mathbf{4 0 . 7 9}$ & $\mathbf{2 3 . 0 6}$ & 45.05 & $157,356.54$ & 0.000 & 0.177 \\
Cultivate self-learning ability & 74.53 & 68.86 & $\mathbf{5 0 . 6 7}$ & $\mathbf{2 6 . 0 7}$ & 57.01 & $327,737.08$ & 0.000 & 0.255 \\
No need to pick up children & 24.24 & $\mathbf{2 3 . 1 7}$ & 23.88 & 24.94 & 23.72 & 686.05 & 0.000 & 0.012 \\
\hline
\end{tabular}

$p<0.001$ : Indicates a significant difference between various satisfaction levels.

self-learning ability. Different students have various comprehension abilities. Therefore, course review is an important way to overcome students' failure to learn knowledge points in class. The self-learning ability of students is also very important in the investigation of students, and the relationship between "cultivate self-learning ability" and satisfaction is the closest, with a medium effect size, Cramer's $V=0.255 .23 \%$ of parents, especially those with "not satisfied" and "average" satisfaction, believe that the advantages of "diverse learning resources" are not obvious. The distinction among parents with different levels of satisfaction in online education is about $10 \%$. There is a tiny difference in the proportion of parents with the four levels of satisfaction in "no need to pick up children". At the same time, Cramer's $V=0.012$ demonstrates that the relationship between "no need to pick up children" and satisfaction is weak. The advantages of online education in picking up children have little effect on parent satisfaction.

\subsubsection{Disadvantages of Online Education}

The chi-square test shows that all $p<0.001$ in Table 10, indicating that the relationship between parent satisfaction and the disadvantage of online education is significant. $85 \%$ of parents think "eyestrain caused by long staring at screens", which shows that most parents take online education's damage on children's eyesight as their primary concern, and it far exceeds the other factors. Compared with the effect of online learning, parents are more concerned about the health of their children. Parents who consider "poor teacher-student interaction" and "lack of group activities, affecting mental development" account for about 50\%, and those who think online education "average" and "not satisfied" account for a higher proportion of these two factors, which mean that parents pay more attention to the communication between teachers and students. Online education is always carried out through electronic equipment and cannot directly feel emotions swing. This is an inevitable deficiency of online education. Parents who are "not satisfied" with online education have major difference in "poor online plat- 
form experience" from "all", reaching about $20 \%$, and have a small-and-medium effect size (Cramer's $V=0.201$ ). It is beneficial for online learning to improve the functions of the platform.

\subsubsection{Parents' Attitudes towards Online Education}

The chi-square test shows that all $p<0.001$ in Table 11, indicating that there is a significant correlation between parent satisfaction and parent online education attitude, with a strong effect size, Cramer's $V=0.380 .86 \%$ of parents believe that online teaching methods can be only used in special periods, so parents are still in conflict with online education. How to transform this thought of parents is the key to making online education become a routine teaching form.

\subsubsection{Habits Cultivated by Online Education}

The chi-square test shows that all $p<0.001$ in Table 12, indicating that there is a significant correlation between parental satisfaction and habits cultivated in online education. $63 \%$ of parents believe that their children "complete homework in time", which is the largest proportion of all online education training habits. And it exceeds the other factors by more than $30 \%$, demonstrating that online education has the greatest influence on students' completing their homework on time. The distinction in "complete homework in time" with different levels of satisfaction is also remarkable. Parents with "very satisfied" are $48 \%$ higher than those with "not satisfied". The experience of students completing their homework can significantly gain parents' approval on online education. "dedicated course" has a middle effect size on parent satisfaction (Cramer's $V=0.323$ ). The difference between "very satisfied" parents and "not satisfied" parents in online education is the largest in the "dedicated course", approaching 56\%, which confirms that online learning is suitable for students who concentrate on learning. Online learning has a greater positive impact on dedicated students. On the contrary, it has a greater negative impact on students with distracted attention.

Table 10. The results on Q13 surveyed parents' perceptions of the disadvantages of online education, and the results are presented as a percentage. All results are calculated by considering parents with varying degrees of satisfaction. The scores in the same row that are lower than the corresponding All value are marked in bold.

\begin{tabular}{cccccccccc}
\hline \multirow{2}{*}{ satisfaction } & $\begin{array}{c}\text { Very } \\
\text { satisfied }\end{array}$ & Satisfied & Average & $\begin{array}{c}\text { Not } \\
\text { Satisfied }\end{array}$ & All & $\chi^{2}$ & Cramer's \\
\hline Poor teacher-student interaction & $\mathbf{3 5 . 4 7}$ & $\mathbf{4 8 . 3 7}$ & 57.91 & 62.29 & 53.35 & $91,863.85$ & 0.000 & 0.135 \\
Poor online platform experience & $\mathbf{1 1 . 6 1}$ & $\mathbf{1 4 . 2 4}$ & 25.73 & 43.66 & 21.95 & $203,984.32$ & 0.000 & 0.201 \\
Insufficient curriculum resources & $\mathbf{8 . 5 3}$ & $\mathbf{9 . 2 5}$ & 16.10 & 27.21 & 13.93 & $104,308.53$ & 0.000 & 0.144 \\
Children addicted to the Internet & $\mathbf{4 4 . 4 5}$ & $\mathbf{5 1 . 8 8}$ & $\mathbf{6 0 . 6 9}$ & $\mathbf{6 9 . 6 1}$ & 57.11 & $77,656.33$ & 0.000 & 0.124 \\
Eyestrain caused by long staring at screens & $\mathbf{7 7 . 2 4}$ & $\mathbf{8 5 . 3 5}$ & $\mathbf{8 5 . 2 5}$ & $\mathbf{8 2 . 0 5}$ & $\mathbf{8 4 . 5 5}$ & $16,557.51$ & 0.000 & 0.057 \\
More cooperation requirements for parents & $\mathbf{1 1 . 9 6}$ & $\mathbf{1 6 . 7 7}$ & 26.38 & 39.01 & 22.89 & $131,041.02$ & 0.000 & 0.161 \\
Lack of group activities, affecting mental & $\mathbf{3 9 . 1 6}$ & $\mathbf{4 7 . 8 3}$ & 52.82 & 57.31 & 50.47 & $33,713.65$ & 0.000 & 0.082 \\
\hline
\end{tabular}

$p<0.001$ : Indicates a significant difference between various satisfaction levels. 
Table 11. The results on Q15 surveyed parents' attitudes towards online education, and the results were presented as a percentage. All results are calculated by considering parents with varying degrees of satisfaction. The scores in the same row that are lower than the corresponding All value are marked in bold.

\begin{tabular}{ccccccccc}
\hline satisfaction & $\begin{array}{c}\text { Very } \\
\text { satisfied }\end{array}$ & Satisfied & Average & $\begin{array}{c}\text { Not } \\
\text { Satisfied }\end{array}$ & All & $\chi^{2}$ & $p$ & $\begin{array}{c}\text { Cramer's } \\
V\end{array}$ \\
\hline Support, online teaching helps learning & 45.49 & 14.85 & 2.96 & $\mathbf{0 . 9 0}$ & 9.80 & & & \\
Support, emergency in special period & 11.61 & 14.24 & 25.73 & 43.66 & 21.95 & $1,455,704.74$ & 0.000 & 0.380 \\
Not support & 8.53 & 9.25 & 16.10 & 27.21 & 13.93 & & \\
\hline
\end{tabular}

$p<0.001$ : Indicates a significant difference between various satisfaction levels.

Table 12. The results on Q16 surveyed parents' beliefs that their children's habits are cultivated by online education, and the results are presented as a percentage. All results are calculated by considering parents with varying degrees of satisfaction. The scores in the same row that are lower than the corresponding All value are marked in bold.

\begin{tabular}{cccccccccc}
\hline satisfaction & Very satisfied & Satisfied & Average & Not Satisfied & All & $\chi^{2}$ & $p$ & Cramer's $V$ \\
\hline Preview & 55.77 & 37.38 & $\mathbf{2 1 . 8 3}$ & $\mathbf{9 . 6 8}$ & 28.74 & $303,440.48$ & 0.000 & 0.245 \\
Dedicated course & 62.66 & 41.64 & $\mathbf{1 8 . 9 9}$ & $\mathbf{6 . 5 8}$ & 29.07 & $527,952.46$ & 0.000 & 0.323 \\
Review & 55.22 & 39.40 & $\mathbf{2 2 . 3 2}$ & $\mathbf{9 . 2 4}$ & 29.65 & $320,576.71$ & 0.000 & 0.252 \\
Complete & 77.49 & 74.08 & $\mathbf{5 7 . 6 0}$ & $\mathbf{2 9 . 1 5}$ & 62.8 & $333,894.19$ & 0.000 & 0.257 \\
homework in time & & & & & & & & \\
Take notes skillfully & 47.34 & 34.26 & $\mathbf{1 9 . 2 0}$ & $\mathbf{7 . 4 4}$ & 25.6 & $268,201.22$ & 0.000 & 0.230 \\
Study plan & 30.95 & 17.63 & $\mathbf{9 . 3 3}$ & $\mathbf{4 . 1 3}$ & 13.33 & $176,127.73$ & 0.000 & 0.187 \\
Submit questions & 24.25 & 13.28 & $\mathbf{8 . 3 4}$ & $\mathbf{5 . 0 3}$ & 10.9 & $98,908.37$ & 0.000 & 0.140 \\
Daily reading & 41.64 & 32.57 & $\mathbf{2 2 . 8 0}$ & $\mathbf{1 1 . 2 8}$ & 26.71 & $132,200.32$ & 0.000 & 0.162 \\
Exam preparation & 20.00 & 9.68 & $\mathbf{4 . 9 2 1}$ & $\mathbf{2 . 4 7}$ & 7.421 & $12,685.13$ & 0.000 & 0.156 \\
Data collation & 31.32 & 21.95 & $\mathbf{1 3 . 0 4}$ & $\mathbf{6 . 2 5}$ & 16.94 & $136,249.95$ & 0.000 & 0.164 \\
\hline
\end{tabular}

\section{Discussion}

\subsection{Students}

For students, teaching techniques, teacher attitudes and levels, and learning resources have diverse level of influence on student satisfaction in online education. Learning resources and platforms have the greatest impact on satisfaction. Abundant learning resources are accessory to broadening our horizons and being exposed to different learning methods, and ultimately we can pick up the learning skills that suit us. At the current stage of e-learning development, there are many types of platforms, such as Zoom, the national primary and secondary school network platform, and Tencent Classroom. A good platform can enhance the efficiency of online learning for students, so they are satisfied with online education. (Jin, 2012) and (Ch \& Popuri, 2013) explain that a suitable teaching platform raises the quality of learning to a high level.

Different regions, including urban and rural areas, and grades have various 
degrees of satisfaction with online education. The economically developed southern students are more satisfied with online education than those in the other regions. However, the differences among students in regions are tiny. Generally speaking, there is an imbalance in the level of education among different regions, but this online education satisfaction survey has achieved regional balance. In the past, almost all regions had only classroom education. It will bring about the tilt of teaching resources as the unbalanced development of regional economy. Therefore, the development of education among various regions is imbalanced. Online learning increases the share of teaching material and alleviates the problem of regional growth disproportion in education.

On the one hand, compared with urban students, rural students are most satisfied with teacher attitudes and teaching skills, followed by online education resources. To increase student satisfaction, rural schools can carry out online teaching training for teachers in the above three parts. On the other hand, compared to primary school students, teachers' teaching attitudes have a more significant impact on students in the later-school-year, especially for junior school students, which shows that senior students have more weight on teachers' emotions. Therefore, later-school-year teachers should sustain emotional stability during the teaching process and not take personal sentiments into the classroom. In addition, high school students also pay more attention to teaching skills, which stimulate the passion of students in learning. Teachers' purpose is to make students understand the complex and tedious knowledge through vivid explanations. Middle school content is much more challenging than that of primary school, so improving teacher skills can strengthen high school students' satisfaction.

\subsection{Teachers}

For teachers, teaching materials, online interaction, teaching platforms, and student engagement have various effects on teacher satisfaction in online education. However, student engagement has the greatest impact on teacher satisfaction. Due to geographical isolation, teachers cannot directly control students, so they can only evaluate students' learning status through students' classroom engagement. (Rabe-Hemp, Woollen, \& Humiston, 2009) scrutinized student participation in online education and traditional teaching models. The results point that student in online classrooms have more thinking and they participate more in classroom discussions. It makes teachers be more satisfied with online education as students are involved in discussing.

Student satisfaction has a pretty tight relationship with online teaching platforms, but teacher satisfaction has a weak connection with teaching platforms. Teachers in urban and rural regions have a distinct emphasis on online teaching platforms. Online learning platforms are more vital to urban teachers. Urban teachers were more exposed to online education than before, and online teaching patterns are diverse, so they will also have higher claims for online teaching platforms. In addition, there is a distinction in teaching materials for different 
grades. Primary school teachers apply an abundance of teaching materials to attract students' attention. Schools and related departments demand to distinguish among grades and select suitable materials.

All local schools should strengthen online teaching technology training for teachers, promote the integration of online teaching and information technology, and carry out content reform and mode innovation. Online education expands the ways of knowledge dissemination, breaking through the limitations of time and space. Thus, online learning and classroom learning are effectively combined to promote the development of education.

\subsection{Parents}

Parent satisfaction in online education is closely linked to student learning status. Parents of dedicated students are more satisfied with online education. However, most students in this survey are in poor learning status, so satisfaction is average. In online teaching, the message notification mechanism of learning electronic devices often disengages students from learning activities and attracts them to enter social media applications (Gikas \& Grant, 2013). We want to make students focus on the curriculum, as well as to strengthen teachers' teaching ability. It is significant to devote themselves to establishing an excellent e-learning environment. How to build a suitable learning environment for online education by improving online education tools and platforms? Focus on this part can effectively improve the quality of online education.

In terms of the perceived advantages of online learning, our results resonate with several previous findings (Appana, 2008; Harvey, Greer, Basham, \& Hu, 2014). Online education has some potential benefits, such as providing convenience, increasing learning opportunities, and developing abilities. In this survey, what is different from the previous ones is that parents regard course review as the most apparent advantage. Online teaching provides students with better review materials, including videos and notes. It should be noted that student participation in activities and interaction with teachers and classmates have an important influence on parental satisfaction. (Jung, Choi, Lim, \& Leem, 2002) investigated the effect of multiple interaction methods on satisfaction. The survey results indicate that no matter what kind of interaction method is, it is an effective way for students to enhance learning efficiency. (Swan, 2001) also states that interaction with teachers and active discussions among course participants significantly affect student satisfaction.

On the disadvantages of online education, parents' main dissatisfaction is that online education makes eye damage to learners. That way provides empirical evidence for (Bhattacharya, Saleem, \& Singh, 2020) suggestion that online learning generates harm to human bodies. This negative impact has a strong relationship with electronic products, which can cause lasting damage to the retina by emitting high-energy waves. From a technical perspective, we can avoid irreparable injury to health by developing electronic products that are less harmful to the body. From the perspective of the teaching plan, sometimes outdoor activities 
should be arranged to avoid prolonged use of electronic equipment to provoke eye discomfort.

This online survey is built during the COVID-19 pandemic. The vast majority of parents regard online education as an alternative to face-to-face education. However, by this attempt, many parents encourage online education as a supplement to face-to-face classrooms. Furthermore, another significant aspect of parents' satisfaction with online education is that they have trained students' self-learning ability. At the same time, online education has developed students' self-regulated learning. (Adam, Alzahri, Soh, Bakar, \& Kamal, 2017) described Self-regulated learning as a catalyst from top-down teaching as well as interactive and cooperative learning methods for passive learners. The self-regulated learning awareness cultivated by online learning benefits students during their life.

\subsection{Implication}

\subsubsection{Technical Support}

Online learning participants encountered technical problems in online learning, including learning platform problems and technical conditions. These problems have varying levels of impact on the satisfaction of students, teachers, and parents (Kauffman, 2015). The Education Bureau and the school should assist both teachers and students who encounter matters and make corresponding plans in different situations.

In areas where the Internet is underdeveloped, local governments and schools should attempt to solve network problems. In regions with low bandwidth, such as rural areas, we should transform teaching methods by converting live to recording and broadcasting and replacing videos with recordings. Develop differentiated education plans based on regional infrastructure development and make online education accessible to students. For the moment, popular devices have been used for online education, including smartphones, pads, and computers. These intelligent devices often distract learners from learning to entertaining, thereby interrupting learning. Using these electronic devices for a long time can also cause eye fatigue. In the future, we can design a dedicated smart device for online teaching, which will neither interfere with learning nor harm the body. The government and relevant departments will popularize the devices in underdeveloped areas.

The satisfaction of online education participants, especially students, is also influenced by the teaching platform. Education bureaus and schools should provide comprehensive guidance and assistance to students and teachers who encounter technical problems using online teaching platforms. Teachers are more experienced than students in applying online teaching platforms. It is necessary to devote more energy to answering students' questions and to make sure that all learners master the functions of online teaching platforms.

\subsubsection{Learning Resources}

Abundant resources are an advantage of online teaching, and we should contin- 
ue to grow this advantage. Education bureaus and schools in township areas should increase their investment in online resources for students, such as highquality courses and reference books. Therefore, the popularization of online education helps reduce the gap in educational resources. The academic pressure of middle and high school students makes them pay more attention to learning resources, so teachers make different learning plans according to different grades. Teacher teaching materials in the western region have a major influence on their satisfaction, and the reasons for this require further research.

\subsubsection{Online Interaction}

Whether teacher-student or student interaction, this is a crucial step in the learning process. Therefore, we should provide more communication opportunities for students in online teaching. (Dabbagh \& Kitsantasm, 2012) believe that students should adopt social media to communicate under the guidance of teachers. Teaching interaction can not only help students immerse themselves in the classroom, but also enhance teachers' enthusiasm for teaching and increase satisfaction. Therefore, it is crucial to create a good communication environment, promoting the evolution of online education. Moreover, the research results show that high school students and primary school students require more frequent communication. Because high school knowledge is unintelligible, communication between student-student and teacher-student can strengthen their understanding. Primary school pupils are curious, communication between each can resolve their doubts. In conclusion, teachers of different grades should concentrate on the arrangement of lessons.

\subsection{Limitations}

This survey respondents are the participants of online education during the COVID-19 epidemic. A part of the experience extends to online teaching in the regular period, and there may be some deviations. The interviewees of this research survey are from Guangdong Province, China. Online education experience may not be applicable to the other areas of China. The data collected in this article are self-reported data, which may be over-reported or under-reported and biased towards society (Gonyea, 2005). In the future, research should obtain objective data through similar online education management systems, having a deeper understanding of learners' behaviors and attitudes.

\section{Conclusion}

In this survey, we explored the factors that affect the satisfaction of participants during the COVID-19 epidemic. At the same time, we also analyzed different regions, different grades, and urban and rural areas. In various situations, people have different opinions on online education. This paper puts forward a few suggestions for the future growth of online education. Firstly, the Bureau of Education and the government should do their best to assist technology and educational resources in remote areas to achieve the extension of online education. 
Thus, it is helpful to reduce the education gap in different regions. Secondly, to make corresponding learning plans for different grades, pay particular attention to providing more communication for high school and primary school students, and providing rich learning resources for junior and high school students. Thirdly, to supply specialized consultants for teachers and students to use the online teaching platform to ensure that participants can master most functions. Finally, a dedicated smart device should be designed for online education, so that learners will not be disturbed by social media applications during the learning time. In addition, another benefit is that it does not damage eyesight. With the advent of the Internet era, the traditional education industry has been affected, and online education is the trend of world education development. According to the research on online education, we can provide accurate teaching services for online education participants in different situations.

\section{Funding}

This paper and the study are funded by: Fund Project 1: NSFC (Project No.: 62077028, 61877029); Fund Project 2: the Science and Technology Planning Project of Guangdong (Project No.: 2021B0101420003, 2020B0909030005, 2020B1212030003, 2019A050510024, 2020ZDZX3013, 2019B1515120010, 2018KTSCX016); Fund Project 3: the Science and Technology Planning Project of Guangzhou (Project No.: 201902010041); Fund Project 4: the teaching reform research projects of Jinan University (Project No.: JG2021112).

\section{Conflicts of Interest}

The authors declare no conflicts of interest regarding the publication of this paper.

\section{References}

Adam, N. L., Alzahri, F. B., Soh, S. C., Bakar, N. A., \& Kamal, N. A. M. (2017). Self-Regulated Learning and Online Learning: A Systematic Review. In H. Badioze Zaman et al. (Eds.), International Visual Informatics Conference (pp. 143-154), Springer. https://doi.org/10.1007/978-3-319-70010-6 14

Appana, S. (2008). A Review of Benefits and Limitations of Online Learning in the Context of the Student, the Instructor and the Tenured Faculty. International Journal on E-Learning, 7, 5-22.

Baber, H. (2020). Determinants of Students' Perceived Learning Outcome and Satisfaction in Online Learning during the Pandemic of Covid-19. Journal of Education and e-Learning Research, 7, 285-292. https://doi.org/10.20448/journal.509.2020.73.285.292

Barbour, M. K., \& LaBonte, R. (2015). State of the Nation: K-12 e-Learning in Canada. Canadian e-Learning Network

Barbour, M. K., \& Reeves, T. C. (2009). The Reality of Virtual Schools: A Review of the Literature. Computers \& Education, 52, 402-416.

https://doi.org/10.1016/j.compedu.2008.09.009

Bhattacharya, S., Saleem, S. M., \& Singh, A. (2020). Digital Eye Strain in the Era of Covid-19 Pandemic: An Emerging Public Health Threat. Indian Journal of Ophthalmolo- 
$g y, 68,1709-1710$. https://doi.org/10.4103/ijo.IJO $1782 \quad 20$

Broadbent, J., \& Poon, W. L. (2015). Self-Regulated Learning Strategies \& Academic Achievement in Online Higher Education Learning Environments: A Systematic Review. The Internet and Higher Education, 27, 1-13.

https://doi.org/10.1016/j.iheduc.2015.04.007

Cavanaugh, C. S., Barbour, M. K., \& Clark, T. (2009). Research and Practice in K-12 Online Learning: A Review of Open Access Literature. The International Review of Research in Open and Distributed Learning, 10, No. 1.

https://doi.org/10.19173/irrodl.v10i1.607

Ch, S. K., \& Popuri, S. (2013). Impact of Online Education: A Study on Online Learning Platforms and Edx. In Proceedings of 2013 IEEE International Conference in MOOC, Innovation and Technology in Education (MITE) (pp. 366-370). Institute of Electrical and Electronics Engineers. https://doi.org/10.1109/MITE.2013.6756369

Chen, T., Peng, L., Yin, X., Rong, J., Yang, J., \& Cong, G. (2020). Analysis of User Satisfaction with Online Education Platforms in China during the Covid-19 Pandemic. Healthcare, 8 , Article No. 200. https://doi.org/10.3390/healthcare8030200

Clark, C., Strudler, N., \& Grove, K. (2015). Comparing Asynchronous and Synchronous Video vs. Text Based Discussions in an Online Teacher Education Course. Online Learning, 19, 48-69. https://doi.org/10.24059/olj.v19i3.510

Cobb, S. (2011). Social Presence, Satisfaction, and Perceived Learning of RN-to-BSN Students in Web-Based Nursing Courses. Nursing Education Perspectives, 32, 115-119. https://doi.org/10.5480/1536-5026-32.2.115

Dabbagh, N., \& Kitsantas, A. (2012). Personal Learning Environments, Social Media, and Self-Regulated Learning: A Natural Formula for Connecting Formal and Informal Learning. The Internet and Higher Education, 15, 3-8. https://doi.org/10.1016/j.iheduc.2011.06.002

de Barba, P. G., Kennedy, G. E., \& Ainley, M. (2016). The Role of Students' Motivation and Participation in Predicting Performance in a MOOC. Journal of Computer Assisted Learning, 32, 218-231. https://doi.org/10.1111/jcal.12130

Diao, L., Niu, D., Zang, Z., \& Chen, C. (2019). Short-Term Weather Forecast Based on Wavelet Denoising and Catboost. In Proceedings of 2019 Chinese Control Conference (CCC) (pp. 3760-3764). Institute of Electrical and Electronics Engineers. https://doi.org/10.23919/ChiCC.2019.8865324

Fornell, C., \& Larcker, D. F. (1981). Evaluating Structural Equation Models with Unobservable Variables and Measurement Error. Journal of Marketing Research, 18, 39-50. https://doi.org/10.1177/002224378101800104

Gikas, J., \& Grant, M. M. (2013). Mobile Computing Devices in Higher Education: Student Perspectives on Learning with Cellphones, Smartphones \& Social Media. The Internet and Higher Education, 19, 18-26. https://doi.org/10.1016/j.iheduc.2013.06.002

Gonyea, R. M. (2005). Self-Reported Data in Institutional Research: Review and Recommendations. New Directions for Institutional Research, 2005, 73-89. https://doi.org/10.1002/ir.156

Gray, J. A., \& DiLoreto, M. (2016). The Effects of Student Engagement, Student Satisfaction, and Perceived Learning in Online Learning Environments. International Journal of Educational Leadership Preparation, 11, 1-20.

Gupta, S., Eastman, J. K., \& Swift, C. O. (2005). Creating an Effective Online Learning Environment: A Shift in the Pedagogical Paradigm. Academy of Educational Leadership Journal, 9, 79-83.

Hair, J. F. (2009). Multivariate Data Analysis. Prentice Hall. 
Harvey, D., Greer, D., Basham, J., \& Hu, B. (2014). From the Student Perspective: Xperiences of Middle and High School Students in Online Learning. American Journal of Distance Education, 28, 14-26. https://doi.org/10.1080/08923647.2014.868739

Hu, L. T., \& Bentler, P. M. (1999). Cutoff Criteria for Fit Indexes in Covariance Structure analysis: Conventional Criteria versus New Alternatives. Structural Equation Modeling, 6, 1-55. https://doi.org/10.1080/10705519909540118

Huang, F., Teo, T., \& Zhou, M. (2020). Chinese Students' Intentions to Use the Internet-Based Technology for Learning. Educational Technology Research and Development, 68, 575-591. https://doi.org/10.1007/s11423-019-09695-y

Islahi, F., \& Nasrin (2019). Exploring Teacher Attitude towards Information Technology with a Gender Perspective. Contemporary Educational Technology, 10, 37-54. https://doi.org/10.30935/cet.512527

Jin, S. (2012). Design of an Online Learning Platform with Moodle. In Proceedings of 2012 7th International Conference on Computer Science \& Education (ICCSE) (pp. 1710-1714). Institute of Electrical and Electronics Engineers. https://doi.org/10.1109/ICCSE.2012.6295395

Jung, I., Choi, S., Lim, C., \& Leem, J. (2002). Effects of Different Types of Interaction on Learning Achievement, Satisfaction and Participation in Web-Based Instruction. Innovations in Education and Teaching International, 39, 153-162. https://doi.org/10.1080/14703290252934603

Kauffman, H. (2015). A Review of Predictive Factors of Student Success in and Satisfaction with Online Learning. Research in Learning Technology, 23, Article ID: 26507. https://doi.org/10.3402/rlt.v23.26507

Kline, R. B. (2015). Principles and Practice of Structural Equation Modeling. Guilford Publications.

Ku, H. Y., Tseng, H. W., \& Akarasriworn, C. (2013). Collaboration Factors, Teamwork Satisfaction, and Student Attitudes toward Online Collaborative Learning. Computers in Human Behavior, 29, 922-929. https://doi.org/10.1016/j.chb.2012.12.019

Leadbeater, W., Shuttleworth, T., Couperthwaite, J., \& Nightingale, K. P. (2013). Evaluating the Use and Impact of Lecture Recording in Undergraduates: Evidence for Distinct Approaches by Different Groups of Students. Computers \& Education, 61, 185-192. https://doi.org/10.1016/j.compedu.2012.09.011

Li, K. (2019). MOOC Learners' Demographics, Self-Regulated Learning Strategy, Perceived Learning and Satisfaction: A Structural Equation Modeling Approach. Computers \& Education, 132, 16-30. https://doi.org/10.1016/j.compedu.2019.01.003

Lundberg, S. M., Erion, G. G., \& Lee, S. I. (2018). Consistent Individualized Feature Attribution for Tree Ensembles. arXiv Preprint arXiv:1802.03888 .

McQuaide, S. (2009). Making Education Equitable in Rural China through Distance Learning. The International Review of Research in Open and Distributed Learning, 10, No. 1. https://doi.org/10.19173/irrodl.v10i1.590

Nagy, J. T., \& Bernschütz, M. (2016). The Impact of Webinar-Webcast System on Learning Performance. Education and Information Technologies, 21, 1837-1845. https://doi.org/10.1007/s10639-015-9422-4

Prokhorenkova, L., Gusev, G., Vorobev, A., Dorogush, A. V., \& Gulin, A. (2017). Catboost: Unbiased Boosting with Categorical Features. arXiv Preprint arXiv:1706.09516 .

Rabe-Hemp, C., Woollen, S., \& Humiston, G. S. (2009). A Comparative Analysis of Student Engagement, Learning, and Satisfaction in Lecture Hall and Online Learning Settings. Quarterly Review of Distance Education, 10, 207-218. 
Recker, M., Giersch, S., Walker, A., Halioris, S., Mao, X., \& Palmer, B. (2007). A Study of How Online Learning Resource Are Used. In Proceedings of the 7th ACM/IEEE-CS Joint Conference on Digital Libraries (pp. 179-180). Association for Computing Machinery. https://doi.org/10.1145/1255175.1255209

Shapley, L. S. (1953). A Value for N-Person Games. In H. W. Kuhn, \& A. W. Tucker (Eds.), Contributions to the Theory of Games (Vol. 1, pp. 307-318). Princeton University Press. https://doi.org/10.1515/9781400881970-018

Swan, K. (2001). Virtual Interaction: Design Factors Affecting Student Satisfaction and Perceived Learning in Asynchronous Online Courses. Distance education, 22, 306-331. https://doi.org/10.1080/0158791010220208

Tibshirani, R. (1996). Regression Shrinkage and Selection via the Lasso. Journal of the Royal Statistical Society: Series B (Methodological), 58, 267-288.

https://doi.org/10.1111/j.2517-6161.1996.tb02080.x

Tibshirani, R. (2011). Regression Shrinkage and Selection via the Lasso: A Retrospective. Journal of the Royal Statistical Society: Series B (Statistical Methodology), 73, 273-282. https://doi.org/10.1111/j.1467-9868.2011.00771.x

Van Lancker, W., \& Parolin, Z. (2020). Covid-19, School Closures, and Child Poverty: A Social Crisis in the Making. The Lancet Public Health, 5, e243-e244. https://doi.org/10.1016/S2468-2667(20)30084-0

Wang, C. H., Shannon, D. M., \& Ross, M. E. (2013). Students' Characteristics, Self-Regulated Learning, Technology Self-Efficacy, and Course Outcomes in Online Learning. Distance Education, 34, 302-323. https://doi.org/10.1080/01587919.2013.835779

Xie, X., Naminse, E., Liu, S., \& Yi, Q. (2020). The Spatial and Temporal Pattern of Covid-19 and Its Effect on Humans' Development in China. Global Journal of Environmental Science and Management, 6, 107-118.

Yan, L., Whitelock-Wainwright, A., Guan, Q., Wen, G., Gašević, D., \& Chen, G. (2021). Students' Experience of Online Learning during the Covid-19 Pandemic: A Province-Wide Survey Study. British Journal of Educational Technology, 52, 2038-2057.

https://doi.org/10.1111/bjet.13102 


\section{Appendix}

Table A1. Student scale.

\begin{tabular}{|c|c|c|c|c|}
\hline item & $\begin{array}{c}\text { Very } \\
\text { satisfied }\end{array}$ & satisfied & Average & $\begin{array}{c}\text { Not } \\
\text { satisfied }\end{array}$ \\
\hline \multicolumn{5}{|l|}{ Lecture webcast } \\
\hline \multicolumn{5}{|l|}{ Lecture recording } \\
\hline \multicolumn{5}{|l|}{ Teacher attitude } \\
\hline \multicolumn{5}{|l|}{ Teacher online teaching skills } \\
\hline \multicolumn{5}{|l|}{ Online learning resources } \\
\hline Online learning platform & & & & \\
\hline
\end{tabular}

Table A2. Teacher scale.

\begin{tabular}{|c|c|c|c|c|}
\hline item & $\begin{array}{c}\text { Very } \\
\text { satisfied }\end{array}$ & satisfied & Average & $\begin{array}{c}\text { Not } \\
\text { satisfied }\end{array}$ \\
\hline \multicolumn{5}{|l|}{ Teaching materials } \\
\hline \multicolumn{5}{|l|}{ Online interaction } \\
\hline \multicolumn{5}{|l|}{ Platform and software } \\
\hline \multicolumn{5}{|l|}{ Student engagement } \\
\hline Contrast classroom teaching & & & & \\
\hline
\end{tabular}

Table A3. Parent questionnaire.

\begin{tabular}{|c|c|}
\hline Question Text & Question Types \\
\hline Q1. What is the location and category of your school? & Single-response MCQ \\
\hline Q2. What grade is your child? & Single-response MCQ \\
\hline Q3. What kind of parent are you? & Single-response MCQ \\
\hline Q4. What is your education level? & Single-response MCQ \\
\hline Q5. In what ways can your child receive online education? & Multiple-response MCQ \\
\hline Q6. Do you accompany your children in online learning? & Single-response MCQ \\
\hline $\begin{array}{l}\text { Q7. How long do you spend studying with your children } \\
\text { every day? }\end{array}$ & Single-response MCQ \\
\hline $\begin{array}{l}\text { Q8. How often do you tutor your child's coursework or } \\
\text { activities? }\end{array}$ & Single-response MCQ \\
\hline $\begin{array}{l}\text { Q9. Can your child independently use the online learning } \\
\text { device? }\end{array}$ & Single-response MCQ \\
\hline Q10. What is your child's online learning status? & Single-response MCQ \\
\hline $\begin{array}{l}\text { Q11. For online learning, what does the school require } \\
\text { parents to cooperate with? }\end{array}$ & Multiple-response MCQ \\
\hline $\begin{array}{l}\text { Q12. What do you think are the benefits of online } \\
\text { education? }\end{array}$ & Multiple-response MCQ \\
\hline
\end{tabular}




\section{Continued}

Q13. What do you think are the disadvantage of online learning?

Q14. Are you satisfied with the effect of online teaching during the epidemic?

Q15. What is your attitude toward online teaching?

Q16. Which of the following learning habits do you think your children have developed through online education during the epidemic?
Multiple-response MCQ

Yes/No Questions

Single-response MCQ

Multiple-response MCQ 